\title{
A proprietary herbal extract against hair loss in androgenetic alopecia and telogen effluvium: a placebo-controlled, single-blind, clinical- instrumental study
}

\author{
Erkin Pekmezci ${ }^{1 凶}$, Cihat Dündar², Murat Türkoğlu²
}

\begin{abstract}
Introduction: Currently there are only a limited number of drugs available for treatment of androgenetic alopecia and telogen effluvium. However, certain plants and their standardized extracts may provide some clinical benefits against hair loss. We formulated a herbal shampoo and a solution to evaluate their efficacy, safety, and synergy in hair loss.

Methods: We conducted a randomized, placebo-controlled, single-blind, clinical and instrumental study for 6 months on 120 subjects with androgenetic alopecia and telogen effluvium, confirmed by pull test and phototricogram. Each subject was examined monthly. At the end of the study, a self-assessment test was carried out.

Results: Herbal formulations were found to be more effective in preventing and reducing hair loss than placebo at every assessment point. Anagen/telogen ratios improved significantly in the study group. In addition, concomitant use of the shampoo and solution were found to be more effective than single product use.

Conclusion: We interpret this eutrophic effect for scalp hair as the final outcome of the entire content of our herbal formula, which has antiandrogenic, anti-inflammatory, antioxidative, angiogenic, and hair-stimulating features. In combination, these features help prevent hair from falling out and reducing hair loss.
\end{abstract}

Keywords: herbal extract, hair loss, clinical study

Received: 11 December 2017 | Returned for modification: 25 January 2018 | Accepted: 26 February 2018

\section{Introduction}

Although hair loss is not a serious problem for general health, it is a matter of concern because it can lower self-confidence and create feelings of inferiority. In general, patients with alopecia have a higher incidence of psychiatric disorders such as depression, anxiety, and social phobia compared to the rest of the population (1).

Although androgenetic alopecia (AGA) is more prevalent in men, it is a widespread dermatological problem that also affects women. Up to $30 \%, 50 \%$, and $80 \%$ of the men affected are over the ages of 30, 50, and 80 respectively. Androgens play an important role that appears to be independent from genetic predisposition, which is considered the main etiologic factor in $\operatorname{AGA}(2,3)$. Testosterone is converted into its more potent form dihydrotestosterone (DHT) by the enzyme 5a-reductase (5a-R). The AGA-prone scalp has high levels of DHT and augmented androgen receptor (AR) expression (4). Inflammatory processes are also increasingly being cited as an integral part in the pathogenesis of AGA (4-8). In AGA, scalp biopsies from both men and women revealed follicular microinflammation and lymphocytic folliculitis, targeting an immunologically driven trigger $(7,8)$. One of the factors leading to permanent hair loss in AGA may be this continuous inflammation and remodeling of the connective tissue of follicles (4).

Telogen effluvium (TE) is another frequent cause of diffuse hair loss, but the true incidence is not well known because of insufficient data, especially due to subclinical cases (9). Although TE may be one manifestation of various chronic systemic illnesses, an association between stress and hair loss is well accepted among clinicians $(10,11)$. The sensitivity of human hair follicles to key skin-stress mediators has been demonstrated: organ-cultured hair follicles responded to substance $\mathrm{P}$ with premature catagen development and degranulation of mast cells in the connective tissue sheath of hair follicles, indicating a neurogenic inflammation (12). Acute TE due to oxidative stress induced by ultraviolet radiation has also been identified. Photoactivation of porphyrin compounds produced by bacteria in the pilosebaceous duct led to oxidative tissue injury and follicular microinflammation (13).

Currently, although topical minoxidil and oral finasteride are the only medications approved for AGA, cause-oriented treatment is performed for TE. Considering the androgenetic and inflammatory factors in the pathogenesis explained above, we formulated a herbal shampoo and solution containing a mixture of six different herbal extracts (HE) with antiandrogenic, anti-inflammatory, and antioxidative features. Our hypothesis was that, if there is a high enough concentration of relevant flavonoids, vitamins, and trace elements at the site of action (i.e., hair follicles), then inflammatory and aging processes can be slowed down and reversed to a certain extent. This study was performed to assess the efficacy, safety, and synergy of the new cosmetic herbal shampoo and solution for treatment of AGA or TE.

\section{Methods}

\section{Products tested}

Herbal shampoo: aqua, sodium laureth sulfate, cocamidopropyl betaine, sodium chloride, mixture of herbal extracts (Urtica urens leaf extract, Urtica dioica root extract, Matricaria chamomilla flower extract, Achillea millefolium aerial part extract, Ceratonia siliqua fruit extract, Equisetum arvense leaf extract), glycerin, benzyl alcohol, perfume/fragrance, PEG/PPG-120/10-trimethylolpropane trioleate, laureth-2, hydroxypropyl guar, hydroxypropyltrimonium 
chloride, polyquaternium-7, amodimethicone, tetrasodium EDTA, menthol, mel, panthenol, C11-15 pareth-7, laureth-9, sodium PCA, butylphenyl methylpropional, trideceth-12, coumarin, hydroxyisohexyl 3-cyclohexene carboxaldehyde, methylchloroisothiazolinone, niacinamide, Panax ginseng root extract, and methylisothiazolinone.

Herbal solution: aqua, mixture of herbal extracts (Urtica urens leaf extract, Urtica dioica root extract, Matricaria chamomilla flower extract, Achillea millefolium aerial part extract, Ceratonia siliqua fruit extract, Equisetum arvense leaf extract), sodium hydroxymethylglycinate, mel, and glycerin.

Placebo shampoo: aqua, sodium laureth sulfate, cocamidopropyl betaine, sodium chloride, E150a (caramel color), glycerin, benzyl alcohol, perfume/fragrance, PEG/PPG-120/10-trimethylolpropane trioleate, laureth-2, hydroxypropyl guar, hydroxypropyltrimonium chloride, polyquaternium-7, amodimethicone, tetrasodium EDTA, menthol, mel, panthenol, C11-15 pareth-7, laureth-9, sodium PCA, butylphenyl methylpropional, Trideceth-12, coumarin, hydroxyisohexyl 3-cyclohexene carboxaldehyde, methylchloroisothiazolinone, niacinamide, Panax ginseng root extract, and methylisothiazolinone.

Placebo solution: aqua, E150a (caramel color), sodium hydroxymethylglycinate, mel, and glycerin. The placebo shampoo and solution did not contain the HE. All of the products tested complied with EU cosmetic regulations and the products were notified in the Cosmetic Products Notification Portal (CPNP) system.

\section{Phytochemical analyses of HE}

Vitamin and flavonoid analyses were performed with high-pressure liquid chromatography (HPLC) at Phytolab, Vestenbergsgreuth, Germany. Trace elements analyses were performed with inductively coupled plasma optical emission spectrometry (ICPOES) at Saniter Lab, Istanbul, Turkey.

\section{Clinical panel and ethical requirements}

The sample consisted of otherwise healthy Caucasian subjects (6o males and 60 females) 20 to 55 years old, suffering from AGA grades II and III in accordance with the Hamilton-Norwood scale or TE, enrolled in the trial (54 AGA subjects, 66 TE subjects) with written informed consent. The subjects were chosen under the control of a dermatologist on the basis of the inclusion/exclusion criteria: the subjects were not using any topical or systemic medications, they had no scalp or hair disease except the trial indications, they had no hypersensitivity history, and none of them were pregnant or lactating. All of the trial procedures were performed in line with the ethical principles laid down for medical research (Helsinki Declaration of World Medical Association, 1964, and amendments). In the event of any unexpected or adverse reaction, a medical investigator was on standby for intervention.

\section{Group formation}

The products' allocations were randomized in accordance with a randomization list. The randomization list was created using Wei's urn algorithm, which is designed to generate balanced random samples throughout the course of an experiment. The following groups were formed: Group A: 30 subjects that used herbal (active) shampoo, Group B: 30 subjects that used herbal (active) solution, Group C: 30 subjects that used herbal (active) shampoo and herbal (active) solution, and Group D: 30 subjects that used placebo shampoo and placebo solution. In addition to the mean/ median ages of the subjects, the gender and clinical distribution in each group are presented in Table 1 . There were no differences in the demographic features among the groups.

Table 1 | Sex and clinical distributions, means \pm standard deviations (SD), and medians of the ages for each group and all subjects.

\begin{tabular}{ccccccc}
\hline Group & Male & Female & AGA & TE & Age (mean \pm SD) & Age (median) \\
\hline A & 15 & 15 & 14 & 16 & $36.6 \pm 10.6$ & 37.0 \\
B & 15 & 15 & 13 & 17 & $37.3 \pm 9.7$ & 37.0 \\
C & 15 & 15 & 13 & 17 & $36.6 \pm 9.7$ & 34.5 \\
D & 15 & 15 & 14 & 16 & $37.0 \pm 9.6$ & 36.0 \\
Total & 60 & 60 & 54 & 66 & $36.9 \pm 9.8$ & 36.5 \\
\hline
\end{tabular}

$\mathrm{AGA}=$ androgenetic alopecia, $\mathrm{TE}=$ telogen effluvium.

\section{Product use}

Shampoo: Every other day, three times a week, apply $5 \mathrm{ml}$ on wet hair, wait for 3 to 4 minutes after foaming, and then rinse well.

Solution: Every day in the morning and in the evening, apply $3 \mathrm{ml}$ on dry hair and massage all over the scalp. Let it stand for at least 4 to 6 hours.

\section{Study design}

After the enrollment and the evaluation of the physiological scalp and hair conditions by the dermatologist (T0), the subjects were informed about the principles of the study. At the end of each month, the subjects were evaluated based on the criteria presented in Table 2.

Table 2 | Summary of the study outline ( $\mathrm{T}=$ Time of evaluation in months).

\begin{tabular}{lccccccc}
\hline Component & T0 & T1 & T2 & T3 & T4 & T5 & T6 \\
\hline Enrollment & X & & & & & & \\
Inclusion criteria & $\mathrm{X}$ & $\mathrm{X}$ & $\mathrm{X}$ & $\mathrm{X}$ & $\mathrm{X}$ & $\mathrm{X}$ & $\mathrm{X}$ \\
Subject compliance & $\mathrm{X}$ & $\mathrm{X}$ & $\mathrm{X}$ & $\mathrm{X}$ & $\mathrm{X}$ & $\mathrm{X}$ & $\mathrm{X}$ \\
Pull test & $\mathrm{X}$ & $\mathrm{X}$ & $\mathrm{X}$ & $\mathrm{X}$ & $\mathrm{X}$ & $\mathrm{X}$ & $\mathrm{X}$ \\
Phototricogram & $\mathrm{X}$ & & $\mathrm{X}$ & & $\mathrm{X}$ & & $\mathrm{X}$ \\
Dermatological evaluations & $\mathrm{X}$ & $\mathrm{X}$ & $\mathrm{X}$ & $\mathrm{X}$ & $\mathrm{X}$ & $\mathrm{X}$ & $\mathrm{X}$ \\
Self-assessment & & & & & & & $\mathrm{X}$ \\
\hline
\end{tabular}

\section{Pull test}

The pull test was used to assess diffuse hair loss. Mild traction was performed on a bunch of hair (approximately 6o fibers) and the number of hairs extracted was counted. Operatively, the dermatologist took a few strands between his thumb and forefinger and pulled them gently. Anagen (growing) hair should remain rooted in place, and telogen (non-growing) hair should come out easily. If the number of lost hairs was greater than six, the pull test was considered positive. Subjects were requested not to wash their hair in the 24 hours before the pull test.

\section{Phototricogram}

A targeted area of $1.8 \mathrm{~cm}^{2}$ was chosen for clipping. This was a zone of transition between normal hair and the balding area in male subjects with AGA, and the middle part of the vertex in TE and female AGA subjects. The shaved hair zone was dyed gray, and photos were taken with a digital close-up camera immediately and 2 days later. By comparing these two consecutive photographs with a software system identifying individual hair fibers, growing (anagen phase) or non-growing (telogen phase) fibers were determined. 


\section{Dermatological evaluation}

The dermatologist clinically evaluated the presence of dandruff, excess sebum, scalp redness, or the onset of an itching sensation.

\section{Self-assessment}

At the end of the study, in month 6 , the subjects were given a 10-point questionnaire on which 1 was the lowest and 10 was the highest score in order to rate the benefit of the treatments on certain hair properties. The questionnaire is presented in Table 3.

Table 3 | Questionnaire given to the subjects at the end of the study.

\begin{tabular}{lcc}
\hline & Questions & Scores \\
\hline 1 & Have you noticed a decrease in hair loss? & 12345678910 \\
2 & Have you noticed the growth of new hair? & 12345678910 \\
3 & Have you noticed an increase in hair thickness? & 12345678910 \\
4 & Has your hair grown faster? & 12345678910 \\
5 & Has the treatment reinforced your hair? & 12345678910 \\
\hline
\end{tabular}

\section{Statistical analyses}

In intragroup evaluation (time course), the Wilcoxon signed-rank test for non-parametric pull test data and repeated measured analysis of variance followed by Student's $t$-test for parametric phototricogram data were used. In intergroup evaluation (active vs. active vs. placebo), the Wilcoxon Kruskal-Wallis one-way analysis of variance on ranks for non-parametric pull test and selfassessment data, and multivariate analysis of variance followed by Student's t-test for parametric phototricogram data were used.

\section{Results}

\section{Phytochemical analyses of HE}

The vitamins, flavonoids, and trace elements found in phytochemical analyses of HE are presented in Table 4. The quantities of all of them are expressed as $\mathrm{mg} / 100 \mathrm{~g}$ dry extract.

\section{Pull test}

The comparison between Group A / shampoo (active) vs. Group B

Table 4 | Vitamins, flavonoids, and trace elements found in phytochemical analyses of HE.

\begin{tabular}{lc}
\hline Component & $(\mathrm{mg} / 100 \mathrm{~g}$ dry extract $)$ \\
Vitamins & 7.4 \\
Thiamin $\left(\mathrm{B}_{1}\right)$ & 1.4 \\
Riboflavin $\left(\mathrm{B}_{2}\right)$ & 1.2 \\
Pyridoxin $\left(\mathrm{B}_{6}\right)$ & $<0.5$ \\
$\quad$ Ascorbic acid $(\mathrm{C})$ & \\
Flavonoids & 1,450 \\
$\quad$ Myricetin & 400 \\
Quercetin & 600 \\
Kaempferol & \\
Trace elements & 53.06 \\
Iron & 0.645 \\
Copper & 2.048 \\
Zinc &
\end{tabular}

/ solution (active) vs. Group C / shampoo (active) + solution (active) vs. Group D / shampoo (placebo) + solution (placebo) are presented in Fig. 1, and the graph reports the mean (\%) decrease obtained for each product tested. The data are reported as mean (\%) variation of hair loss during the pull test for each month (T1T6) compared to the beginning of the trial (T0). Although the intragroup statistical analyses revealed significant improvement in all groups for all months compared to T0, the intergroup analyses showed that Group C (active shampoo + solution) had the best clinical outcomes and Group D (placebo shampoo + solution) had the worst. The $p$ values of the intergroup analyses are presented in Table 5. Fig. 1 also shows that longer usage of products corresponds to better clinical outcomes.

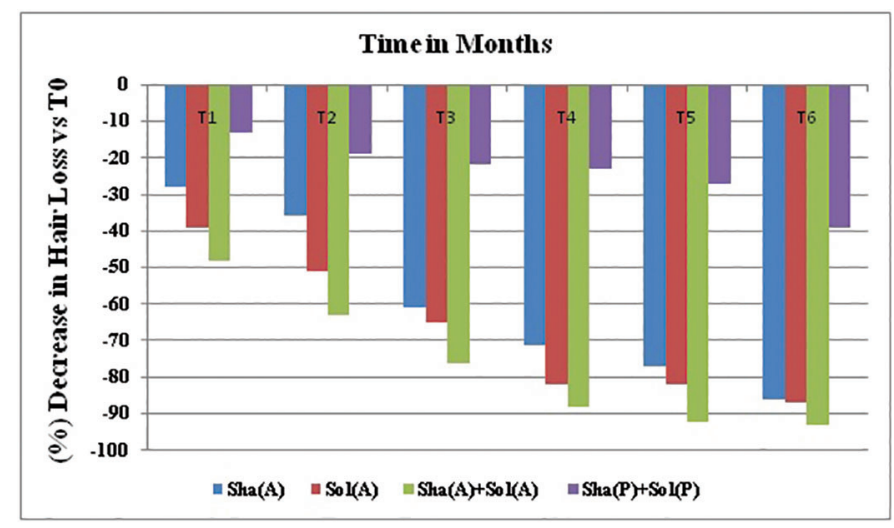

Figure 1 | Summary of pull test results. (\%) decrease in hair loss for each month (T1-T6) compared to the beginning of the trial (T0). Group A / shampoo (active) vs. Group B / solution (active) vs. Group C / shampoo (active) + solution (active) vs. Group D / shampoo (placebo) + solution (placebo).

\section{Phototrichogram}

Whereas there was no increase in group D (placebo shampoo + solution) during the study, the number of total hairs in groups $\mathrm{A}$ (active shampoo), B (active solution), and C (active shampoo + solution) increased significantly in month 4 (T4) and month 6 (T6) compared to the beginning of the trial (T0, Fig. 2).

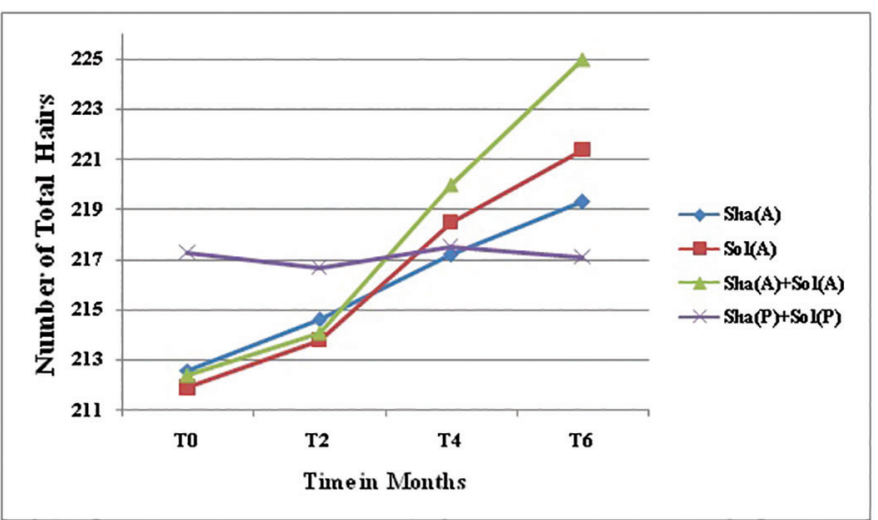

Figure 2 | Increase in number of total hairs from the beginning of the trial (T0) to the month 6 (T6) for every 2 months. The $p$ values of Group A / shampoo (active), Group B / solution (active) and Group C / shampoo (active) + solution (active) in T4 and T6 were $<0.001$; whereas T2 was > 0.05 compared to T0. All of the values (i.e., T2-T6) of Group D / shampoo (placebo) + solution (placebo) were > 0.05 compared to TO.

Table 5 | The $p$ values of Group C / shampoo (active) + solution (active) vs. Group A / shampoo (active), Group B / solution (active), and Group D / shampoo (placebo) + solution (placebo) for months 1 through 6, each month (T1-T6) compared to the beginning of the trial (T0).

\begin{tabular}{|c|c|c|c|c|c|c|}
\hline Group & T1 & T2 & T3 & T4 & T5 & T6 \\
\hline Sha $(A)+\operatorname{Sol}(A)$ vs. Sha $(A)$ & 0.000568 & 0.000042 & 0.001583 & 0.000194 & 0.000002 & 0.013762 \\
\hline $\operatorname{Sha}(A)+\operatorname{Sol}(A)$ vs. Sol $(A)$ & 0.741908 & 0.046241 & 0.037569 & 0.070589 & 0.010426 & 0.049356 \\
\hline $\operatorname{Sha}(A)+\operatorname{Sol}(A)$ vs. Sha $(P)+\operatorname{Sol}(P)$ & 0.000001 & 0.000001 & $<0.000001$ & $<0.000001$ & $<0.000001$ & $<0.000001$ \\
\hline
\end{tabular}

Sha $=$ shampoo, Sol = solution, $(A)=$ active, $(P)=$ placebo. 
The decrease in telogen hairs and increase in anagen hairs were also significant in groups $\mathrm{A}, \mathrm{B}$, and $\mathrm{C}$ in $\mathrm{T} 4$ and $\mathrm{T} 6$ compared to $\mathrm{T} 0$ (Figs. 3-5). The (\%) changes in telogen and anagen hairs through T2-T6 in group D were not significant (Fig. 6).

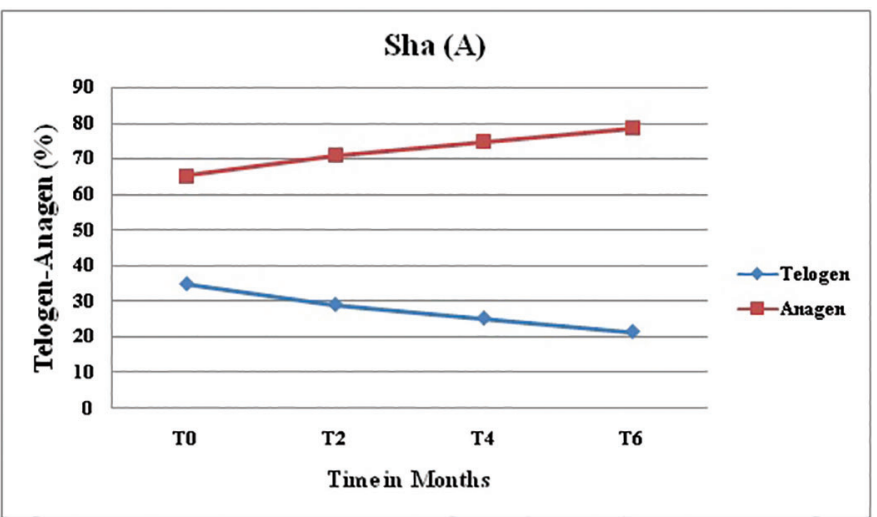

Figure 3 | Telogen-anagen (\%) changes for Group A / shampoo (active) for every 2 months. The $p$ values for both telogen and anagen changes in T2-T6 were $<0.001$ compared to T0.

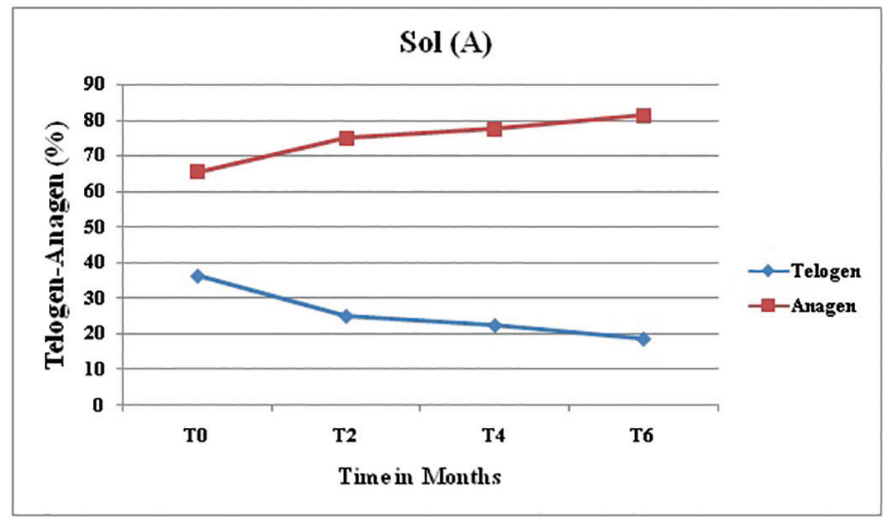

Figure 4 | Telogen-anagen (\%) changes for Group B / solution (active) for every 2 months. The $p$ values for both telogen and anagen changes in T2-T6 were $<0.001$ compared to T0.

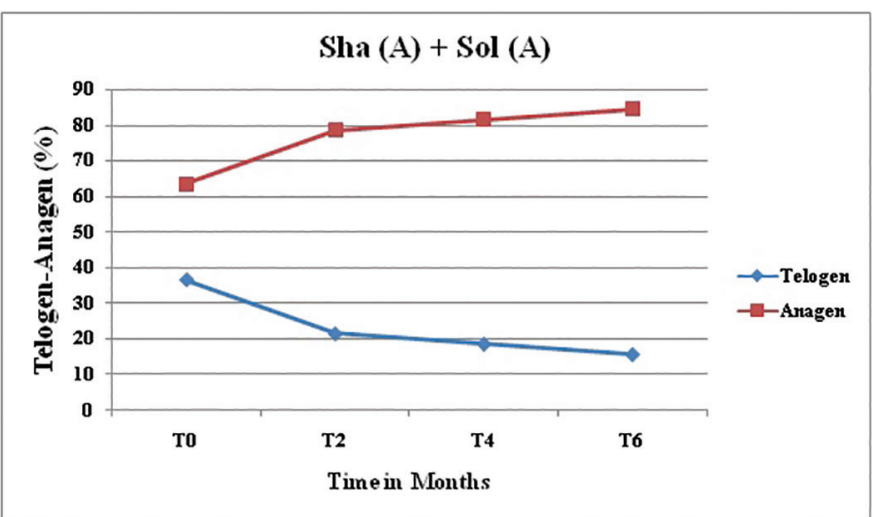

Figure 5 | Telogen-anagen (\%) changes for Group C / shampoo (active) + solution (active) for every 2 months. The $p$ values for both telogen and anagen changes in T2-T6 were $<0.001$ compared to T0.

\section{Self-assessment}

Fig. 7 presents the mean scores of self-assessment questions. The highest scores are from Group C (active shampoo + solution), and

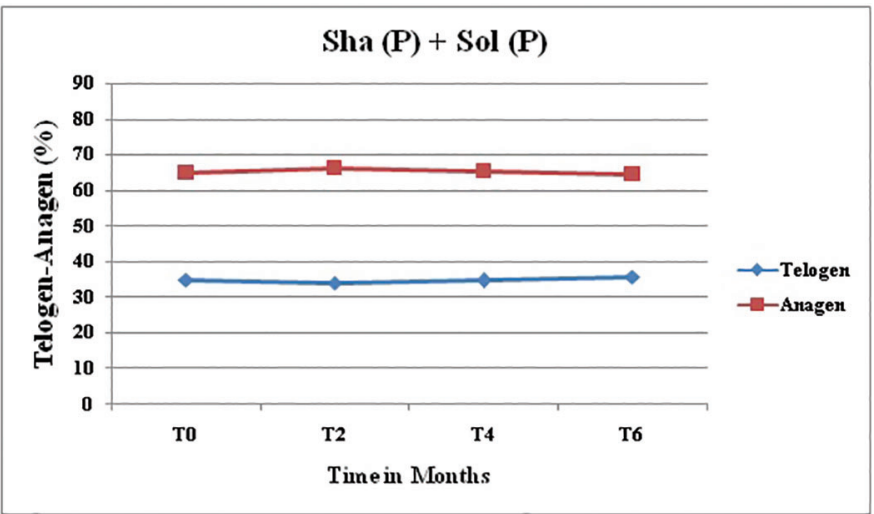

Figure 6 | Telogen-anagen (\%) changes for Group D / shampoo (placebo) + solution (placebo) for every 2 months. The $p$ values for both telogen and anagen changes in T2-T6 were > 0.05 compared to T0.

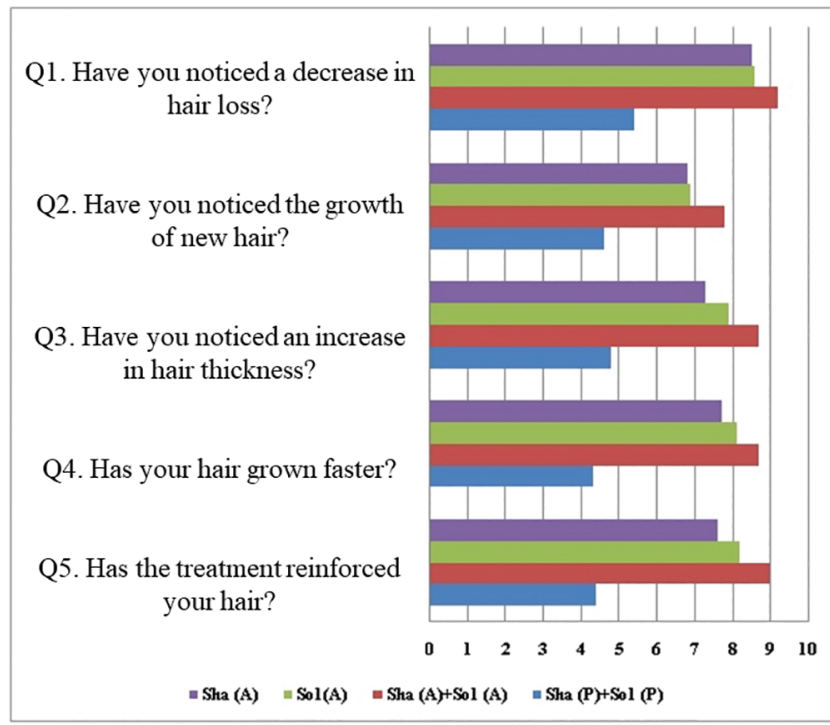

Figure 7 | Results of self-assessment questions for the treatments and placebo.

the lowest scores are from Group D (placebo shampoo + solution). In statistical evaluation of the self-assessment data, all of the questions showed statistically significant results based on the difference from placebo. Here Group $\mathrm{C}$ also has the best clinical outcomes and Group D the worst. The $p$ values of intergroup analyses for each question are presented in Table 6.

\section{General considerations for clinical-instrumental results}

The products were well tolerated and no side effects were recorded during the study. The herbal/active shampoo and solution helped ameliorate the baseline conditions of subjects suffering from AGA or TE. In this 6-month study, the regular use of the herbal shampoo and/or solution decreased hair loss and increased the number of anagen hairs. These effects, clinically or instrumentally confirmed, were also perceived by the subjects participating in the study and significantly delineated in the statistical analyses of self-assessment results. The results obtained in the group that used both active products (shampoo and solution) were sig-

Table 6 | The $p$ values of Group C / shampoo (active) + solution (active) vs. Group A / shampoo (active), Group B / solution (active), and Group D / shampoo (placebo) + solution (placebo) for each self-assessment question. All of the values are statistically significant.

\begin{tabular}{|c|c|c|c|c|c|}
\hline Group & Q1 & Q2 & Q3 & Q4 & Q5 \\
\hline Sha $(A)+\operatorname{Sol}(A)$ vs. Sha $(A)$ & 0.031921 & 0.017811 & 0.000336 & 0.001156 & 0.000034 \\
\hline $\operatorname{Sha}(A)+\operatorname{Sol}(A)$ vs. Sol $(A)$ & 0.027737 & 0.024259 & 0.027002 & 0.028522 & 0.013295 \\
\hline $\operatorname{Sha}(A)+\operatorname{Sol}(A)$ vs. Sha $(P)+\operatorname{Sol}(P)$ & $<0.000001$ & $<0.000001$ & $<0.000001$ & $<0.000001$ & $<0.000001$ \\
\hline
\end{tabular}

Sha $=$ shampoo, Sol = solution, $(A)=$ active, $(P)=$ placebo. 
nificantly better than those obtained in the groups that used only one active product (shampoo or solution). The concomitant use of herbal shampoo and herbal solution had a synergistic effect in improving the parameters measured.

\section{Discussion}

The causes for the clear significant positive results of the products tested should be sought in the interaction between the properties of the plants in our HE and etiopathogenetic factors in the hair loss types included in this study.

Among the plants used in the formulation, Urtica dioica (Ud) is the most widely studied. The use of Ud root extract in symptomatic benign prostate hyperplasia $(\mathrm{BPH})$ and lower urinary tract symptoms has been investigated in numerous clinical trials and found effective (14-17). This indication is mainly due to its $5 a-R$ inhibition activity $(18,19)$. Inhibition of $5 a-R$ hampers the formation of DHT from testosterone. An excess amount of DHT is related to $\mathrm{BPH}(17)$. The same pathogenesis is also true for $\operatorname{AGA}(4,5)$, and this mechanism of action may be the main cause of the success of our formulation in patients with AGA. Although Ud leaves have traditionally been used for hair loss, confirmatory clinical trials are still lacking (17). In a study performed with a combination of herbal extracts including Ud, it was shown that the combination enhanced human dermal papilla cell proliferation at concentrations between $1.5 \%$ and $4.5 \%$ (20).

As stated in the introduction to this report, apart from the pathogenesis of AGA related to androgen metabolism, inflammatory and oxidative processes are the basic common pathways in the etiopathogenesis of both AGA and TE (4-13). Polysaccharides and caffeic malic acid (CMA) both exist to some extent in every part of Ud. Urtica polysaccharides and CMA present anti-inflammatory activity by inhibiting cyclooxigenase and lipoxygenase $(21,22)$. $\beta$ sitosterol, also a component of Ud, stimulates angiogenesis by increasing vascular endothelial growth factor (VEGF) synthesis and supports new hair growth (23). This molecule also suppresses testosterone synthesis and contributes to decreased DHT levels (24).

The proximate analysis results showed that leaf extract of Urtica urens $(\mathrm{Uu})$ contains a high amount of total phenolics, flavonoids, tannins, ortho-diphenols, and flavonols $(25,26)$. It has been shown to decrease paw edema after carrageenin administration in rats and to improve the activities of catalase, superoxide dismutase, glutathione peroxidase, and malondialdehyde, exhibiting powerful antioxidant and anti-inflammatory activity (26).

In a study performed with Equisetum arvense (Ea) alone and with a combination of some other plants, Ea suppressed superoxide anion levels in the xanthine/xanthine oxidase system and eliminated the hydroxyl radical. Ea also reduced reactive oxygen species (ROS) in neutrophils that were stimulated by phorbol myristate acetate. In the same study, although carrageenin-induced paw swelling in rats was significantly inhibited by the plant mixture, this inhibition could not be achieved by the components on an individual basis (27). This phenomenon could explain why our plant mixture also had a synergistic effect in obtaining the good outcomes in the study. In addition to various studies depicting its antioxidative features (28-30), Ea exhibited significant diabetic wound healing by showing higher epidermal and dermal regeneration, angiogenesis, and granulation tissue thickness in diabetic rats (31). Ea is one of the highest silicon accumulators among plant species. Silicon penetrates the hair follicles, enters in the hair matrix, and makes the hair fibers thicker. Therefore, the higher the silicon quantity in the hair, the lower the extent of hair loss $(32,33)$.

Leaves and flowers of Achillea millefolium (Am) have been used for centuries for their anti-inflammatory effect in conditions such as rheumatism, wound healing, and skin inflammation (34). In an in vivo study performed with Am oil extract on artificially irritated skin, the parameters tested (i.e., pH, capacitance, and erythema index) were restored to basal values after 3 to 7 days of treatment (35). Am extract showed an augmentation in cytokeratin-10, transglutaminase-1, and filaggrin expressions, together with an increase in the thickness of epidermis in cultured skin biopsies. In addition, a 2-month topical application of 2\% Am extract significantly improved the outlook of wrinkles and pores in vivo when compared with placebo (36).

Historically, oil of Matricaria chamomilla (Mc, German chamomile) has been used in the treatment of some inflammatory dermatoses. It contains three major sesquiterpene compounds (i.e., azulene, bisabolol, and farnesene) with anti-inflammatory or antihistamine effects. Among them, a-bisabolol has the strongest anti-inflammatory effect $(37,38)$. In a study performed with $3 \%$ Mc oil topically on the skin of mice showing its immunoregulatory potential, it alleviated atopic dermatitis through influencing helper T cell 2 (Th2) activation (39). Mc extract applied topically also showed wound healing potential in a linear incisional model in rats (40). A pharmacologically active flavonoid apigenin that is contained by both Mc and Am supports hair growth by suppressing transforming growth factor- $\beta 1$ (TGF- $\beta 1$ ), which stimulates the catagen phase in the hair growth cycle $(41,42)$.

Ceratonia siliqua (Cs) pod extract presents antioxidant features due to its catechin, epicatechin, epigallocatechin, epigallocatechin gallate, and epicatechin gallate contents, along with simpler phenolics, such as phloroglucinol, pyrogallol, catechol, and gallic acid (43-45). In addition, Cs fibers exhibit higher antioxidant capacity than many edible products rich in polyphenols, such as blueberries, grapes, or red wine $(46,47)$.

On the other hand, the flavonoids, vitamins, and trace elements we found in the phytochemical analyses of our formulation may offer more specific support for the wellbeing of hair physiology. Myricetin, quercetin, kaempferol, and copper keep the hair follicle in the anagen phase longer by inhibiting 5a-R type 2 and preventing DHT formation $(48,49)$. Vitamin B complex and vitamin C (ascorbic acid) enhance blood vessel formation and increase blood flow in the scalp by stimulating the synthesis of VEGF (50). It was reported that mice that were exposed to high amounts of environmental cigarette smoke developed alopecia, and this was precluded by administration of 1-cystine and vitamin $\mathrm{B}_{6}$ (pyridoxine) combination (51). B-group vitamins and l-cystine mixtures are also customarily used in OTC products for hair loss (52). Vitamin $B_{2}$ (riboflavin) is known to enhance the metabolism of vitamin $\mathrm{B}_{6}(53,54)$. Vitamin $\mathrm{C}$ might improve the efficacy of therapeutic angiogenesis by cell transplantation (55). Some derivatives of vitamin $\mathrm{C}$ were also found to be promising in treating and preventing DHT-induced balding (56). Iron is a crucial cofactor for the enzymes implicated in energy metabolism and DNA synthesis. It is a fundamental element for healthy skin, mucous membranes, hair, and nails. In the case of scalp hair, iron deficiency leads to dryness and fragility (57). Zinc is found in the enzyme systems affecting hair formation, and local zinc ions stimulate scalp cellular formation (50). Zinc metabolism disturbances play a key role in hair loss, especially in AGA and TE (58). 
The results obtained in this study demonstrate that the products tested have a eutrophic effect on scalp hair, and we interpret this effect as the final outcome of the entire content of the HE for- mulation, which has antiandrogenic, anti-inflammatory, antioxidant, angiogenic, and hair-stimulating features. These features together help prevent "hair fall" and reduce hair loss.

\section{References}

1. Hunt N, McHale S. The psychological impact of alopecia. BMJ. 2005;331:951-3.

2. Rathnayake D, Sinclair R. Male androgenetic alopecia. Expert Opin Pharmacother. 2010;11:1295-304.

3. Bienova M, Kucerova R, Fiuraskova M, Hajduch M, Kolar Z. Androgenetic alopecia and current methods of treatment. Acta Dermatoven APA. 2005;14:5-8.

4. Trüeb RM. Molecular mechanisms of androgenetic alopecia. Exp Gerontol. 2002;37:981-90.

5. Mahé YF, Buan B, Billoni N, Loussouarn G, Michelet JF, Gautier B, et al. Proinflammatory cytokine cascade in human plucked hair. Skin Pharmacol. 1996; 9:336-75.

6. Hirsso P, Rajala U, Hiltunen L, Jokelainen J, Keinanen-Kiukaanniemi S, Näyhä S. Obesity and low-grade inflammation among young Finnish men with earlyonset alopecia. Dermatology. 2007;214:125-9.

7. El-Domyati M, Attia S, Saleh F, Abdel-Wahab H. Androgenetic alopecia in males: a histopathological and ultrastructural study. J Cosmet Dermatol. 2009;8:8391.

8. Magro CM, Rossi A, Manhas-Bhutani S, Sadick N. The role of inflammation and immunity in the pathogenesis of androgenetic alopecia. J Drugs Dermatol. 2011;10:1404-11.

9. Grover C, Khurana A. Telogen effluvium. Indian J Dermatol Venereol Leprol. 2013;79:591-603.

10. Arck PC, Handjiski B, Peters EM, Peter AS, Hagen E, Fischer A, et al. Stress in hibits hair growth in mice by induction of premature catagen development and deleterious perifollicular inflammatory events via neuropeptide substance $P$ dependent pathways. Am J Pathol. 2003;162:803-14.

11. Malkud S. A hospital-based study to determine causes of diffuse hair loss in women. J Clin Diagn Res. 2015;9:WC01-4.

12. Peters EM, Liotiri S, Bodo E, Hagen E, Biro T, Arck PC, et al. Probing the effects of stress mediators on the human hair follicle. Am J Pathol. 2007;171:1872-86.

13. Trüeb RM. Is androgenetic alopecia a photoaggravated dermatosis? Dermatology. 2003;207:343-8.

14. Nahata A, Dixit VK. Ameliorative effects of stinging nettle (Urtica dioica) on testosterone-induced prostatic hyperplasia in rats. Andrologia. 2012;44:396-409.

15. Sökeland J. Combined sabal and urtica extract compared with finasteride in men with benign prostatic hyperplasia: analysis of prostate volume and therapeutic outcome. BJU International. 2000;86:439-42.

16. Lichius JJ, Lenz C, Lindemann P, Müller HH, Aumüller G, Konrad L. Antiproliferative effect of a polysaccharide fraction of a $20 \%$ methanolic extract of stinging nettle roots upon epithelial cells of the human prostate (LNCaP). Pharmazie. 1999;54:768-71.

17. Urtica dioica; Urtica urens (nettle). Monograph. Altern Med Rev, 2007;12:280-4.

18. Nahata A, Dixit VK. Evaluation of 5 a-reductase inhibitory activity of certain herbs useful as androgens. Andrologia. 2014;46:592-601.

19. Hartmann RW, Mark M, Soldati F. Inhibition of 5 a-reductase and aromatase by PHL-00801 (Prostatonin), a combination of PY102 (Pygenum africanum) and UR102 (Urtica dioica) extracts. Phytomedicine. 1996;3:121-8.

20. Rastegar H, Ashtiani HA, Aghaei M, Barikbin B, Ehsani A. Herbal extracts induce dermal papilla cell proliferation of human hair follicles. Ann Dermatol. 2015;27:667-75.

21. Wagner H, Willer F, Samtleben R, Boos G. Search for the antiprostatic principle of stinging nettle (Urtica dioica) roots. Phytomedicine. 1994;1:213-24.

22. Obertreis B, Giller K, Teucher T, Behnke B, Schmitz H. Anti-inflammatory effect of Urtica dioica folia extract in comparison to caffeic malic acid. Arzneimittelforschung. 1996;46:52-6. German.

23. Saeidnia S, Manayi A, Gohari AR, Abdollahi M. The story of beta-sitosterol - a review. European J Med Plants. 2014;4:590-609.

24. Prager N, Bickett K, French N, Marcovici G. A randomised, double-blind, placebo-controlled trial to determine the effectiveness of botanically derived inhibitors of 5-a reductase in the treatment androgenetic alopecia. J Altern Complement Med. 2002;2:143-52.

25. Mzid M, Ben Khedir S, Ben Salem M, Regaieg W, Rebai T. Antioxidant and antimicrobial activities of ethanol and aqueous extracts from Urtica urens. Pharm Biol. 2017;55:775-81.

26. Mzid M, Ben Khedir S, Bardaa S, Sahnoun Z, Rebai T. Chemical composition, phytochemical constituents, antioxidant and anti-inflammatory activities of Urtica urens L. leaves. Arch Physiol Biochem. 2017;123:93-104.

27. Oka M, Tachibana M, Noda K, Inoue N, Tanaka M, Kuwabara K. Relevance of anti-reactive oxygen species activity to anti-inflammatory activity of components of eviprostat, a phytotherapeutic agent for benign prostatic hyperplasia. Pytomedicine. 2007;14:465-72.
28. Guilherme dos Santos I Ir, Hoffmann Martins do Monte F, Marcela Blanco M, Maria do Nascimento Bispo Lanziotti V, Damasseno Maia F, Kalyne de Almeida Leal L. Cognitive enhancement in aged rats after chronic administration of Equisetum arvense L. with demonstrated antioxidant properties in vitro. Pharmacol Biochem Behav. 2005;81:593-600.

29. Oh H, Kim DH, Cho JH, Kim YC. Hepatoprotective and free radical scavenging ac tivities of phenolic petrosins and flavonoids isolated from Equisetum arvense. J Ethnopharmacol. 2004;95:421-4.

30. Mimica-Dukic N, Simin N, Cvejic J, Jovin E, Orcic D, Bozin B. Phenolic compounds in field horsetail (Equisetum arvense) as natural antioxidants. Molecules. 2008; 13:1455-64.

31. Ozay Y, Kasim Cayci M, Guzel-Ozay S, Cimbiz A, Gürlek-Olgun E, Sabri Ozyurt $M$. Effects of Equisetum arvense ointment on diabetic wound healing in rats. Wounds. 2013;25:234-41.

32. Vivancos J, Deshmukh R, Grégoire C, Rémus-Borel W, Belzile F, Bélanger RR. Identification and characterization of silicon efflux transporters in horsetail (Equisetum arvense). J Plant Physiol. 2016;200:82-9.

33. Araújo LA, Addor F, Campos PM. Use of silicon for skin and hair care: an approach of chemical forms available and efficacy. An Bras Dermatol. 2016;91:331-5.

34. Ghobadian Z, Ahmadi MR, Rezazadeh L, Hosseini E, Kokhazadeh T, Ghavam S. In vitro evaluation of Achillea millefolium on the production and stimulation of human skin fibroblast cells (HFS-PI-16). Med Arch. 2015;69:212-7.

35. Tadić V, Arsić I, Zvezdanović J, Zugić A, Cvetković D, Pavkov S. The estimation of the traditionally used yarrow (Achillea millefolium L. Asteraceae) oil extracts with anti-inflammatory potential in topical application. J Ethnopharmacol. 2017; 199:138-48.

36. Pain S, Altobelli C, Boher A, Cittadini L, Favre-Mercuret M, Gaillard C, et al. Surface rejuvenating effect of Achillea millefolium extract. Int J Cosmet Sci. 2011;33: $535-42$.

37. Carle R, Gomaa K. The medicinal use of Matricaria flos. Br J Phytother. 1992;2: 147-53.

38. Standen MD, Myers SP. The roles of essential oils in the modulation of immune function and inflammation: survey of aromatherapy educators. Int J Aromather. 2004;14:150-61.

39. Lee SH, Heo Y, Kim YC. Effect of German chamomile oil application on alleviating atopic dermatitis-like immune alterations in mice. J Vet Sci. 2010;11:35-41.

40. Jarrahi M, Vafaei AA, Taherian AA, Miladi H, Rashidi Pour A. Evaluation of topical Matricaria chamomilla extract activity on linear incisional wound healing in albino rats. Nat Prod Res. 2010;24:697-702.

41. Jesionek W, Móricz ÁM, Ott PG, Kocsis B, Horvath G, Choma IM. TLC-direct bioautography and LC/MS as complementary methods in identification of antibacterial agents in plant tinctures from the Asteraceae family. J AOAC Int. 2015;98:857-61.

42. Huh S, Lee J, Jung E, Kim SC, Kang JI, Lee J, et al. A cell-based system for screening hair growth-promoting agents. Arch Dermatol Res. 2009;301:381-5.

43. Hajaji HE, Lachkar N, Alaoui K, Cherrah Y, Farah A, Ennabili A, et al. Antioxidant activity, phytochemical screening, and total phenolic content of extracts from three genders of carob tree barks growing in Morocco. Arab J Chem. 2011;4:321-4.

44. Milek Dos Santos L, Tomzack Tulio L, Fuganti Campos L, Ramos Dorneles M, Carneiro Hecke, Kruger C. Glycemic response to carob (Ceratonia siliqua L) in healthy subjects and with the in vitro hydrolysis index. Nutr Hosp. 2014;31:482-7.

45. Karim AA, Azlan A. Fruit pod extracts as a source of nutraceuticals and pharmaceuticals. Molecules. 2012;17:11931-46.

46. Haber B. Carob fibre benefits and applications. Cereal Foods World. 2002;47: 365-9.

47. Durazzo A, Turfani V, Narducci V, Azzini E, Maiani G, Carcea M. Nutritional characterisation and bioactive components of commercial carobs flours. Food Chem. 2014;15:109-13.

48. Hiipakka RA, Zhang HZ, Dai W, Dai Q, Liao S. Structure-activity relationships for inhibition of human 5 alpha-reductases by polyphenols. Biochem Pharmacol. 2002;63:1165-76.

49. Sugimoto Y, Lopez Solache I, Labrie F, Luu-The V. Cations inhibit specifically type I 5 a-reductase found in human skin. J Invest Dermatol. 1995;104:775-8.

50. Semalty M, Semalty A, Joshi GP, Rawat MS. Hair growth and rejuvenation: an overview. J Dermatolog Treat. 2011;22:123-32.

51. D’Agostini F, Fiallo P, Pennisi TM, De Flora S. Chemoprevention of smokeinduced alopecia in mice by oral administration of L-cystine and vitamin B6. J Dermatol Sci. 2007;46:189-98.

52. Lengg N, Heidecker B, Seifert B, Trüeb RM. Dietary supplement increases anagen hair rate in women with telogen effluvium: results of a double-blind placebo-controlled trial. Therapy. 2007;4:59-65. 
53. Perry GM, Anderson BB, Dodd N. The effect of riboflavin on red-cell vitamin B6 metabolism and globin synthesis. Biomedicine. 1980;33:36-8.

54. Kodentsova VM, Vrzhesinskaia OA, Sokol'nikov AA, Beketova NA, Spirichev VB. The effect of riboflavin supply on metabolism of water-soluble vitamins. Vopr Med Khim. 1993;39:29-33. Russian.

55. Takeshita Y, Katsuki Y, Katsuda Y, Kai H, Saito Y, Arima K, et al. Vitamin C reversed malfunction of peripheral blood-derived mononuclear cells in smokers through antioxidant properties. Circ J. 2008;72:654-9.
56. Kwack MH, Kim MK, Kim JC, Sung YK. L-ascorbic acid 2-phosphate represses the dihydrotestosterone-induced dickkopf-1 expression in human balding dermal papilla cells. Exp Dermatol. 2010;19:1110-2.

57. Wright JA, Richards T, Srai SK. The role of iron in the skin and cutaneous wound healing. Front Pharmacol. 2014;5:156.

58. Kil MS, Kim CW, Kim SS. Analysis of serum zinc and copper concentrations in hair loss. Ann Dermatol. 2013;25:405-9. 